is single, and leads downwards and backwards in the median line, being enveloped in the tissue passing from the foramen directly to the roof of the thalamencephalon.

I have not yet actually traced the nerve itself into the brain, but it is difficult to imagine that it can possibly arise as a branch from a cranial nerve, being single and medianly placed, and, as just said, enveloped in the material running directly to the roof of the brain from the foramen.

There can be little doubt that it represents the stalk connecting the distal with the proximal outgrowth from the roof of the thalamencephalon, this part having apparently disappeared in other reptiles and amphibia (so far as is yet known).

This being the case it is extremely interesting to observe that another instance will be added to that of the optic nerves in which an, at first, hollow outgrowth from the brain becomes solid and transformed into a nerve, and further that the latter, as in the former case, is connected with an organ of vision.

Though it is difficult to imagine what can be the use of the organ in its present state, seeing it is deeply embedded in connective tissue--so deeply as almost to

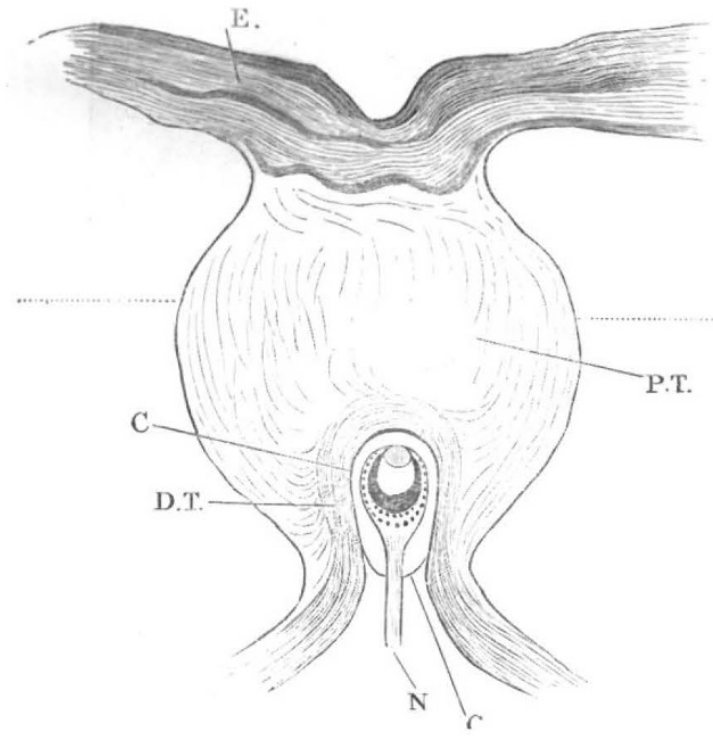

FIG. 2.-Transverse section through parietal foramen of Ha teria punctata. The part below. the dotted line is situated within the parietal foramen.

preclude the idea of its being affected by light-yet it is important as showing in the same animal eyes developed in both the vertebrate and invertebrate type as regards the arrangement of the layers.

In connection with this subject, it is perhaps of interest to point out that in formation of the paired eyes invagination to form an optic cup takes place, whilst apparently it does not do so in the case of what may be called the parietal eye. A little consideration shows that the relative position of the rods depends entirely upon this invagination. In both cases they are formed upon the inner surface of the wall in the position corresponding to the epithelium of the neural canal: but in the one instance they are, by decay of the outer wall of the invaginated cup, placed apparently on the outside of the optic vesicle; whilst in the other instance they are formed in a similar position, but, as no invagination takes place and subsequent decay of one wall, they line the cavity of the vesicle. According to this we must suppose that the part of the wall where the lens is present has either disappeared or become modified into this.

We may further observe that in both types of eye the nerve enters into connection with the elements on the surface opposite to that on which the rods are developed. In conclusion my thanks are due to Prof. Moseley for his kindness in drawing my attention to the subject, and to Mr. E. B. Poulton, of Keble College, Oxford, who kindly placed two specimens of Hatteria at my disposal, and to $\mathrm{Mr}$. Beddard, of the Zoological Society, for the use of another specimen. W. BALDWIN SPENCER Anatomical Department, University Museum, Oxford

NotE.-Since writing the above I have found the eye present in several other lizards, notably in Iguana, Chameleo vulgaris and Lacerta ocellata, and have traced the nerve into the proximal part of the epiphysis.

\section{ASTRONOMICAL PHOTOGRAPHY 1}

SOME attempts made last year at photographing the heavens by means of an instrument quite rudimentary having yielded good resilts, the director of the Paris Observatory gave orders for the construction of a special apparatus, the design of which is shown in the accompanying figure (Fig. I). The mechanical part has been executed in a highly remarkable manner by our accomplished artist, M. Gautier; the objective is our own production.

This new instrument is composed of two telescopes in juxtaposition inclosed in a single metallic tube in the form of a parallelopiped, and separated from each other along their whole length by a narrow partition.

One of the object-glasses, with an aperture of $0^{\circ} 24 \mathrm{~m}$. and a focal length of $3.60 \mathrm{~m}$., is intended for eye observation, and serves as a pointer. The other, with an aperture of $0.34 \mathrm{~m}$. and a focus of $3.43 \mathrm{~m}$., is achromatised for the chemical rays, and serves the purpose of photography. The optical axes of these two objectives being parallel, every star kept in the centre of the field of the eye-piece belonging to the first telescope produces its impression in the centre of the sensitive plate of the photographic apparatus.

The equatorial is mounted in the form called English, that is to say, the centre of the tube rests always in the polar axis of the instrument. This arrangement allows of a star being followed from its rising to its setting without involving the necessity of bringing the instrument back to the vicinity of the meridian. Like a common equatorial it is furnished with hour circle and circle of declination, and with a clock movement keeping the apparatus in operation for three hours without fresh remounting. There are, moreover, independent very slow movements, whereby the axis of the telescope can be kept on a fixed point in the heavens, notwithstanding some slight irregularity in the movement of the clock. work, the orientation of the telescope, or the variations of atmospheric refraction.

The photographic objective-the largest ever yet produced-is formed according to a simple achromatic system, and, though of an extremely short focal length, is able, without the use of any diaphragm, exactly to cover the very considerable field of $3^{\circ}$ diameter.

Although but very recently mounted, this apparatus has already availed for the performance of numerous tasks. On star photographs it is possible to distinguish traces of stars of the 15 th magnitude, too feebly marked, however, to bear transference on paper. The stars of the I 4 th magnitude are reproduced with a diameter of $1 / 40$ of a millimetre.

It is obvious that such small points might be liable to be confounded with the impurities of the sensitive coating if the precaution is not taken to multiply the stationary points. Each star is formed by a group of three points constituting an equilateral triangle, each side of which is no more than $1 / 12$ of a millimetre. To the naked eye these three points appear to merge into one, but on eximining them with the aid of a somewhat I From an article by the Brothers Henry in La Nature. 


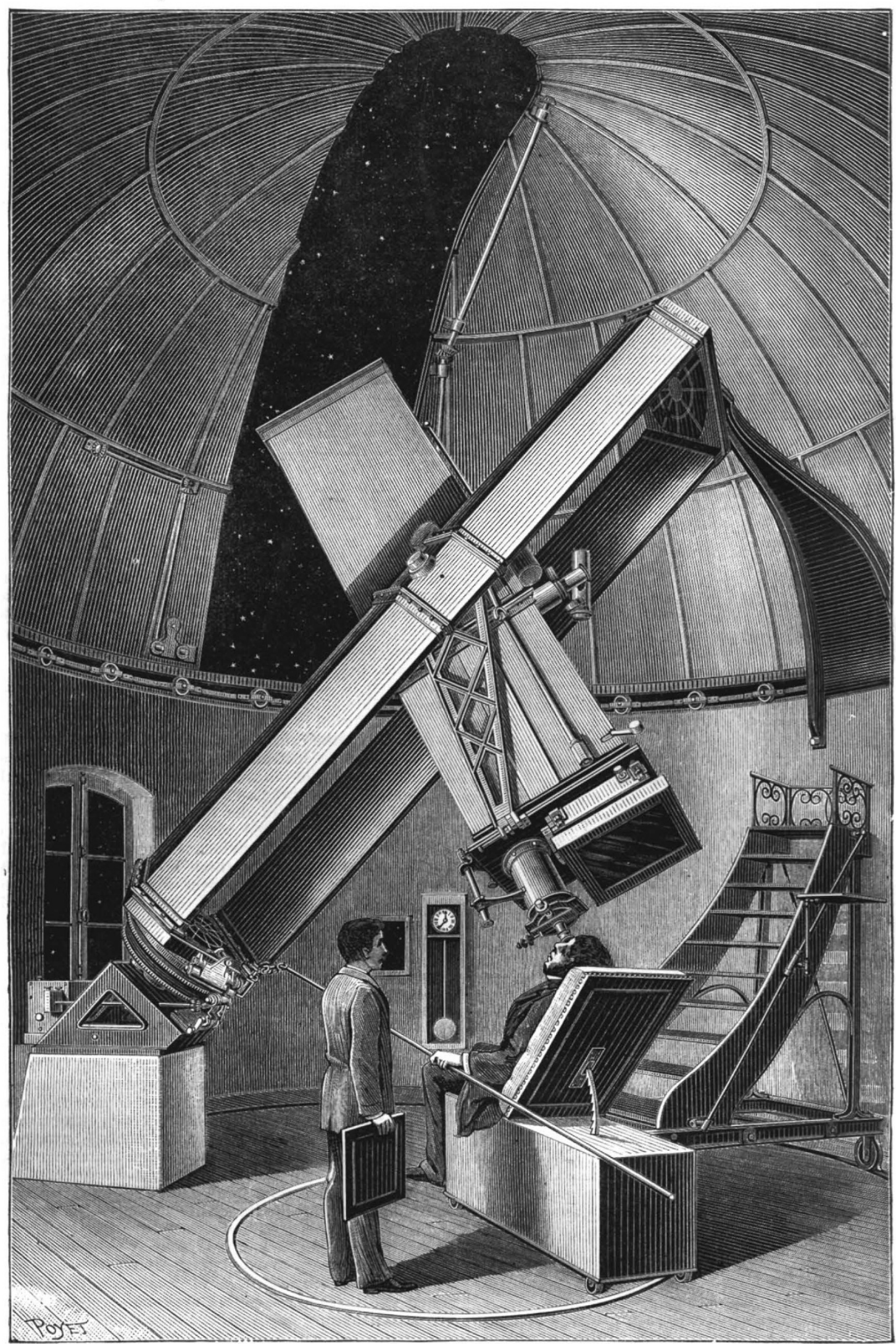

FIG. I. - Parallactic apparatus newly established at the Paris Observatory for celestial photography. 
powerful lens the three points come out distinctly, and it is then an easy task to eliminate all that does not belong to the heavens.

The construction of such a map, obtained by the apparatus as above described in three hours, would assuredly have demanded several months of assiduous labour by the ordinary processes.

The following is the time of exposure requisite to obtain the image of the stars.

\begin{tabular}{|c|c|c|c|c|c|c|c|c|}
\hline$\underset{\text { I }}{\text { Magnitude }}$ & & & & & & & & s. \\
\hline I & $\cdots$ & $\cdots$ & $\cdots$ & $\cdots$ & $\cdots$ & 0 & 0 & 0.005 \\
\hline 2 & $\cdots$ & $\cdots$ & $\cdots$ & $\cdots$ & $\ldots$ & 0 & 0 & O.0I3 \\
\hline 3 & $\cdots$ & $\cdots$ & $\cdots$ & $\cdots$ & $\ldots$ & 0 & 0 & $0: 03$ \\
\hline 4 & $\cdots$ & $\cdots$ & $\cdots$ & $\cdots$ & $\cdots$ & 0 & 0 & 0.08 \\
\hline 5 & $\ldots$ & $\cdots$ & $\cdots$ & $\cdots$ & $\cdots$ & 0 & 0 & 0.2 \\
\hline 6 & $\begin{array}{l}\text { The } \\
\text { of } s\end{array}$ & $\begin{array}{l}\text { tren } \\
\text { s vi }\end{array}$ & $\begin{array}{l}\text { imit } \\
\text { e to }\end{array}$ & $\begin{array}{l}\text { mag } \\
\text { nal }\end{array}$ & $\left.\begin{array}{l}\text { ude } \\
\text { eye }\end{array}\right\}$ & 0 & 0 & 0.5 \\
\hline 7 & $\cdots$ & $\cdots$ & $\cdots$ & $\cdots$ & $\ldots$ & 0 & 0 & I'3 \\
\hline & $\cdots$ & $\cdots$ & $\cdots$ & $\cdots$ & $\cdots$ & 0 & 0 & 3 \\
\hline 9 & $\cdots$ & $\cdots$ & $\cdots$ & $\cdots$ & $\cdots$ & 0 & 0 & 8 \\
\hline I0 & $\dddot{x}$ & $\cdots$ & ... & $\ldots$ & $\ldots$ & 0 & 0 & 20 \\
\hline II & Mea & angr & deo & east & ids & 0 & 0 & 50 \\
\hline 12 & $\cdots$ & $\cdots$ & $\cdots$ & $\cdots$ & $\cdots$ & 0 & 2 & 0 \\
\hline I 3 & $\ldots$ & $\cdots$ & $\ldots$ & $\ldots$ & $\ldots$ & 0 & 5 & 0 \\
\hline 14 & $\ldots$ & $\cdots$ & $\ldots$ & $\because$ & $\therefore$ & 0 & 13 & 0 \\
\hline $\begin{array}{l}\text { I5 } \\
16\end{array}$ & $\begin{array}{l}\text { The } \\
\text { the }\end{array}$ & $\begin{array}{l}\text { st of } \\
\text { d of } t\end{array}$ & $\begin{array}{l}\text { star } \\
\text { grea }\end{array}$ & sib & $\left.\begin{array}{l}\text { ith } \\
\text { nts }\end{array}\right\}$ & I & 23 & 0 \\
\hline
\end{tabular}

All the above figures represent a minimum. To secure good reproductions on paper the time of exposure would have to be increased threefold.

The above table shows that the time of exposure required in taking a star of the first, and that in taking a star of the last magnitude differ from each other as I : I, $, 00,000$. (The relation adopted between the brightnesses of two consecutive magnitudes is 2.542 .)

Outside the construction of celestial maps, another field of study of great importance now created by photography may be cited, the discovery, namely, of the asteroids. The little stars fixing themselves on the plate as so many mathematical points, so to say, the planets are dis tinguished therefrom, each by a little line perfectly defined indicating its proper movement in amount and direction during the time of exposure of the apparatus. It is in this way we have already succeeded in obtaining the trace of a small planet of the IIth magnitude which by a small line extremely well defined gave account of its march among the fixed stars.

It will even be possible to study the movement of the satellites round their planet, and perhaps discover new ones.

The study of the double and multiple stars will be greatly facilitated, and photography will be equally available in the investigation of the parallaxes.

Finally, photometry must be adduced as one of the branches of astronomy which will now be able to collect very valuable information through the utilisation of photography.

In conclusion, it is worth while remarking how this fresh step in advance has sensibly enlarged the scope of man's vision. In consequence of it we can now obtain the image of a star, which instruments of the same opening as those employed by photography would never of themselves have elicited out of their invisibility.

PAUl et Prosper Henry

\section{NOTES}

THE first soirée of the Royal Society this season took place last night. A large number of Fellows and visitors were present, and many objects of interest were exhibited.

THe visitation of the Royal Observatory by the Board of Visitors is fixed this year for June 5 .

${ }^{x}$ For these results we have made use of the gelatino-bromide plates of Monckhoven.
THE Royal Irish Academy is celebrating the centenary of its foundation this week.

DR. Gill, Her Majesty's Astronomer at the Cape, has been elected Corresponding Member of the Imperial Academy of Sciences of St. Petersburg.

THE fifty-seventh anniversary meeting of the Zoological Society was held on Thursday week. The chair was taken by Prof. Flower, LL.D., F.R.S., the President. The report of the Council on the proceedings of the Society during the year was read by Mr. P. L. Sclater, F.R.S., Secretary of the Society. It stated that the number of Fellows on December 3I, 1885, was 3193 , showing a decrease of 62 as compared with the corresponding period in $\mathbf{I} 884$. The total receipts for $\mathbf{I} 885$ had amounted to $25,809 l$. Ios. it $d$., being a decrease of $3129 l$. as compared with the previous year. This decrease was mainly due to the falling off in the receipts under the head of admissions to Gardens, and in the amounts received for admission and composition fees from newly elected Fellows. The ordinary expenditure for 1885 had been 24,593l. I s . 8d, against 26,539l. $4 s$. $1 d$. for 1884 . Besides that, an extraordinary expenditure of $49 \mathrm{r} l$. os. $6 d$. had been incurred, which brought up the total expenditure for the year to $25,084 l$. I2s. $2 d$. The visitors to the Society's Gardens during the year $1885^{\circ}$ had been 659,896 , against 745,460 in 1884 . The Davis Lectures on zoological subjects, having been well attended during the past year, would be continued during the present season, beginning with a lecture on "Pigs and their Allies," by Prof. Flower, LL.D., F.R.S., on Thursday, June 3 , at $5 \mathrm{p.m}$. The number of animals in the Society's collection on December $3 \mathrm{I}$ last was $255 \mathrm{I}$, of which 756 were mammals, 1366 birds, and 429 reptiles. Among the additions made during the past year 21 were specially commented upon as of remarkable interest, and in most cases new to the Society's collection. About. 36 species of mammals, 15 of birds, and 4 of reptiles had bred in the Society's Gardens during the summer of 1885 . The report concluded with a long list of the donors and their various donations to the menagerie during the past year.

WITH regard to the recent explosion of the 43 -ton gun, it is fortunate that it has happened without loss of life. Competent authorities, as seen from Col. A. Moncrieff's letter (which we reproduce from the Times) show that it could. How long are our gun factories to go on making guns condemned by easily-understood scientific principles? "Col. Maitland's interesting paper read at the Royal United Service Institution on June 20, I884," Col. Moncrieff writes, "published the process adopted at Woolwich in settling the types of the new steel breech-loading ordnance for the British service, as well as the proportions of the new guns on these types then in process of manufacture. Mr. W. Anderson's investigations, published in a lecture read before the Society of Arts on January 29, 1885, and also commented upon in the Engineer of February 6, 1885, clearly demonstrated that these guns were deficient in strength in front of the trunnions. It is a remarkable fact that several of the guns have now burst at the point and in the manner which could have been predicted by any one consulting Mr. Anderson's demonstrated results. As the subject is of vital importance to the country, it would seem wise either to refute Mr. Anderson or accept his method and consult him; his valuable service in having discovered the prevailing error and worked ont this most difficult problem is too little known; it would thus be utilised and acknowledged to the advantage of the service. By treating a gun as a heat-engine and accounting for every part of the energy generated by the explosion of the powder, he has, in a scientific and complete manner, proved that the metal crusher gauges from which the accepted curve of pressure is obtained are not to be relied on. 